\title{
ALCOHOL CONSUMPTION AMONG MEN AND WOMEN WITH TUBERCULOSIS IN TOMSK, RUSSIA
}

\author{
Sonya S. Shin ${ }^{1,2,3}$, Trini A. Mathew ${ }^{4}$, Galina V. Yanova ${ }^{5}$, Garrett M. Fitzmaurice ${ }^{6,7,8}$, Viktoriya Livchits ${ }^{1,9}$, \\ Sergey A. Yanov ${ }^{5}$, Aivar K. Strelis ${ }^{10,11}$, Sergey P. Mishustin ${ }^{10}$, Nicolai A. Bokhann ${ }^{12}$, Charmaine S. Lastimoso ${ }^{1}$, \\ Hilary S. Connery ${ }^{7,13}$, J essica E. Hart ${ }^{1}$, Shelly F. Greenfield ${ }^{7,13}$ \\ 'Division of Global Health Equity, Brigham and Women's Hospital, Boston, MA, United States \\ 2Department of Global Health and Social Medicine, Harvard Medical School, Boston, MA, United States \\ ${ }^{3}$ Partners In Health, Boston, MA, United States \\ ${ }^{4}$ Division of Infectious Diseases, University of Mississippi Medical Center, J ackson, MS, United States \\ ${ }^{5}$ Tomsk Oblast C linical Tuberculosis Hospital, Tomsk, Russian Federation \\ ${ }^{6}$ Department of Biostatistics, Harvard School of Public Health, Boston, MA, United States \\ 'Department of Psychiatry, Harvard Medical School, Boston, MA, United States \\ ${ }^{8}$ Division of General Medicine, Brigham and Women's Hospital, Boston, MA, United States \\ 9Partners In Health Russia, Tomsk, Russian Federation \\ ${ }^{10}$ Tomsk Oblast Tuberculosis Services, Tomsk, Russian Federation \\ ${ }^{11}$ Siberian State Medical University, Tomsk, Russian Federation \\ ${ }^{12}$ Institute of Mental Health, Tomsk Research Center, Siberian Division of the Russian Academy of Medical Sciences, Tomsk, Russian Federation \\ ${ }^{13}$ Alcohol and Drug Abuse Treatment Program, McLean Hospital, Belmont, MA, United States
}

\section{SUMMARY}

Drinking behavior among Russian women remains poorly described. We analyzed gender differences in alcohol use among 374 tuberculosis patients in Tomsk, Siberia. Twenty-six (28.3\%) women had lifetime alcohol abuse or dependence, compared with $70.6 \%$ of men. Women with alcohol use disorders drank $12.7 \pm 14.0$ standard drinks per day and $34.6 \%$ drank $\geq$ three days per week. Among individuals with a lifetime alcohol use disorder, age of onset and typical consumption did not differ significantly by gender. We conclude that Russian women with alcohol use disorders consume almost as much alcohol as men and may be at greater risk for negative social and medical consequences.

Key words: women, gender, alcohol use disorders, tuberculosis, Russia, review

Address for corres pondence: S. Shin, Division of Global Health Equity, Brigham and Women's Hospital, FXB Building, 7th Floor, 651 Huntington Avenue, Boston, MA 02115, USA. E-mail: sshin@ partners.org

\section{INTRODUCTION}

With the greatest estimated consumption of alcohol per capita in the world, Russia and the Former Soviet Union (FSU) are among the regions most critically impacted by alcohol use disorders (AUDs) (1, 2). While alcohol use and abuse has long been prevalent in Russia, rates of alcohol consumption rose dramatically after the collapse of the Soviet Union in 1991 (3). Subsequent market reforms permitted a further rise in alcohol sales; by 1995, $5-10 \%$ of people in adult age groups drank more than 100 grams of alcohol per day (4). In 1999, the number of officially reported individuals with alcohol dependence in Russia was 2.2 million, $1.5 \%$ of the total population (5). Because of under-reporting and the lack of internationally-validated criteria to classify alcohol use disorders, most experts agree that official reporting and survey data greatly underestimate the true prevalence of AUDs (6).

In fact, several studies using validated diagnostic instruments have confirmed higher rates of AUDs relative to official estimates. In a survey of 855 rural inhabitants seeking primary care in Udmurtia, Russia, $90.2 \%$ of the adult population reported alcohol use; among these, the lifetime prevalence of harmful alcohol use based on the tenth International Classification of Diseases (ICD-10) (7) criteria was 37.1\% (8), of whom 31.9\% had alcohol dependence. Of those who reportedly tried to stop drinking, only 5\% were abstinent for more than 12 months (8). In a study conducted among urban patients seen at primary care clinics in St. Petersburg, only $2.4 \%$ of the total population reported abstinence, $16.3 \%$ were classified as hazardous drinkers, $9.1 \%$ as harmful drinkers, and $6.1 \%$ had alcohol dependence according to Diagnostic and Statistical Manual Fourth Edition (DSM-IV) criteria using the Composite International Diagnostic Interview (CIDI) $(5,9,10)$.

Alcohol consumption has contributed to the marked rise in mortality in Russia over the past two decades. Between 1992 and 2001, it is estimated that an excess of 2.5-3 million Russian adults died in middle age than would be expected based on 1991 
mortality estimates (11). By 2001, life expectancy had dropped to 66 years, compared with 78 years for U.S. residents (12). Most experts consider alcohol to be the most important factor driving Russian mortality trends; some estimate that alcohol is implicated directly or indirectly in approximately one-third of all Russian deaths $(5,6,13-16)$. Because men disproportionately bear the burden of mortality due to alcohol, much of the literature on the “alcohol crisis" in Russia has focused on men (17-23). Little attention has been given to the fact that, among Russian women, the probability of dying between the ages of 15 and 60 is almost twice that of women in the United States (15.3\% versus $8.2 \%)$ (12) and 4.7 out of 10,000 deaths among Russian women are directly due to alcohol (24).

Despite growing awareness and concern about AUDs in Russia, the problem of AUDs among women remains a "hidden epidemic" (25). While estimates from Russia and other FSU countries report less drinking among women compared with men (26), alcohol consumption is increasing among women, in particular among youth (27). Further, the magnitude of gender differences in AUD prevalence may be overestimated due to underreporting among women. For instance, while a national survey of Russian adults in 1996 found 9\% of males and 35\% of women to have reported abstinence in the past year, alcohol experts estimated the true rate of past year abstinence to be $9 \%$ among males and only $8 \%$ among females (28). Laatikainen et al. observed lower rates of self-reported alcohol consumption among women in the Republic of Karelia, Russia versus North Karelia in Finland, while biological markers of drinking did not differ (29). This discordance between biological markers and self-report - observed only among Russian women and not among men - was interpreted as a greater propensity to under-report alcohol consumption among Russian women due to cultural differences of normative drinking behavior among men versus women (30). Several cohort studies suggest that habitual drinking and alcohol use disorders among women greatly exceed official and survey estimates. Kristjanson et al. found that $96 \%$ of women sampled from employment and educational centers reported consuming alcohol, and $42-55 \%$ of women were heavy to moderate drinkers (i.e. >6.51 ml/d) (31). Similarly, Pakriev et al. found that $54.6 \%$ of women in rural Udmurtia were heavy to moderate drinkers and $10.3 \%$ had an AUD by ICD-10 criteria $(7,8)$.

The cultural norms of drinking and gender roles in Russian society profoundly shape drinking behaviors, as well as reporting accuracy (32). While heavy alcohol consumption (especially binge drinking) is a normative pattern of male socialization in Russia (32), public drinking among women has traditionally been less acceptable (27). Studies exploring the social context of alcohol consumption by gender have shown mixed results. In a sample of Muskovites, Cockerham et al. found that psychological distress and economic deprivation were not associated with increased alcohol consumption in either gender, but rather, that heavy drinking was considered a positive social activity (33). On the other hand, Jukkala et al. reported that, among 1,190 Muskovites, economic and social influences were indeed predictors of binge drinking, but these relationships were strongly gender-dependent (34). Among men, economic strain was associated with binge drinking, whereas among women, the opposite was observed. Moreover, in this cohort, women were more influenced by their social network: being single and having regular contact with friends were both associ- ated with binge drinking. In other words, unlike men, women who drank tended to be those most buffered from social and economic stress. Because both studies sampled well-educated Muskovites and did not consider the use of surrogate spirits - home-brewed alcohols that are less expensive and easily accessible - findings are not likely representative of the broader Russian population, many of whom are impoverished and marginalized.

Although the influence of gender on the health consequences of AUDs in Russia remains largely unexplored, a few studies highlight some gender-specific health consequences of alcohol consumption. While the global rate of fetal alcohol syndrome is 1.9 per 1000 live births (35), fetal alcohol syndrome in Russia is estimated at 53 to 145 per 1000 (36). In a survey of 200 pregnant women in St. Petersburg, 60\% reported drinking even when they knew they were pregnant and $35 \%$ reported drinking in the past 30 days, despite adequate knowledge of the detrimental effects of alcohol on pregnancy outcomes (31). Similarly, among pregnant women in Moscow, Chambers et al. found that 52\% reported alcohol consumption in the past month, including heavy drinking ( $\geq 3$ drinks) in eleven percent.

While limited, these studies highlight the heightened vulnerability and needs of Russian women with AUDs. However, the drinking patterns and health seeking behavior of Russian women with AUDs have not been explored. In particular, gender differences in drinking behaviors and consequences have not been studied among patients seeking care for medical disorders including infectious diseases such as tuberculosis (TB). Alcohol use disorders are prevalent among patients who seek treatment for TB $(37,38)$ and adversely affect TB treatment outcomes (38-45). There is no current information on gender differences in drinking patterns and AUDs among individuals seeking treatment for TB. To address this knowledge gap, we analyzed gender differences in alcohol use patterns and disorders in a prospective cohort study of men and women receiving tuberculosis treatment in Tomsk, Siberia.

\section{METHODS}

\section{Study Setting}

We carried out this study in Tomsk Oblast of Western Siberia, Russia, which has a population of 1,200,000. In 2007, the tuberculosis incidence in Tomsk was 102.7 per 100,000 and TB mortality was 12.2 per 100,000 (46). The Tomsk Oblast TB Services (TOTBS) provides TB care and management for all civilians in the in-patient TB Oblast Hospital, TB Day Hospital, and in the TB Polyclinic. Patients from outlying rural regions generally initiate treatment in the inpatient hospital, whereas residents of Tomsk City may start treatment as an inpatient or outpatient, depending on their clinical status.

\section{Study Participants}

A total of 374 adults starting TB treatment in one of the three TB treatment sites in Tomsk, Russia were enrolled in this study between November 2005 and December 2008. All patients starting TB treatment during this period were referred for study enrollment. 
Table 1. Baseline clinical and demographic characteristics of cohort $(N=374)$

\begin{tabular}{|c|c|c|c|}
\hline Variable (N, if not complete cohort) & $\begin{array}{c}\text { Female } \\
\mathrm{N}=92\end{array}$ & $\begin{array}{c}\text { Male } \\
\mathrm{N}=282\end{array}$ & p-value \\
\hline Age (Mean \pm STD) & $36.4 \pm 11.4$ & $41.1 \pm 11.2$ & 0.0007 \\
\hline Civil status, $N=373$ & & & 0.05 \\
\hline Married & $29(31.5)$ & $77(27.3)$ & \\
\hline Separated & $2(2.2)$ & $30(10.6)$ & \\
\hline Divorced & $18(19.6)$ & $72(25.5)$ & \\
\hline Widowed & $7(7.6)$ & $16(5.7)$ & \\
\hline Never married & $36(39.1)$ & $86(30.5)$ & \\
\hline Unemployed, $N=364$ & $54(58.7)$ & $163(59.9)$ & 0.84 \\
\hline Disability pension, $\mathrm{N}=364$ & $6(6.5)$ & $19(7.0)$ & 1.00 \\
\hline Prior incarceration, $\mathrm{N}=364$ & $5(5.4)$ & $77(28.3)$ & $<0.0001$ \\
\hline \multicolumn{4}{|l|}{ Medical conditions } \\
\hline Cardiovascular and/or cerebrovascular disorder & $4(4.4)$ & $17(6.0)$ & 0.79 \\
\hline HIV, $N=357$ & $0(0)$ & $1(0.4)$ & 1.00 \\
\hline Chronic HBV & $2(2.2)$ & $2(0.7)$ & 0.25 \\
\hline Elevated liver function tests, $\mathrm{N}=363$ & $31(33.7)$ & $101(37.3)$ & 0.54 \\
\hline \multicolumn{4}{|l|}{ TB condition } \\
\hline No prior TB treatment & $80(86.9)$ & $220(78.0)$ & 0.06 \\
\hline Low body mass index, $\mathrm{N}=364$ & $40(43.5)$ & $51(18.8)$ & $<0.0001$ \\
\hline Bilateral and cavitary abnormalities on chest radiograph, $\mathrm{N}=363$ & $28(30.4)$ & $124(45.8)$ & 0.01 \\
\hline
\end{tabular}

\section{Data Collection}

TB physicians completed a standardized form providing baseline clinical and demographic data at the time of TB treatment initiation. This included baseline Alcohol Use Disorder Identification Test (AUDIT) score (47), as well as TB treatment history. We used the Composite International Diagnostic Interview-Substance Abuse Module (CIDI-SAM) $(5,10)$ to assess alcohol use disorders (alcohol abuse and dependence) according to DSM-IV criteria (9). Information on drug use disorders (abuse or dependence) based on DSM-IV criteria, social consequences of drinking and help-seeking behaviors for drinking were also derived from the CIDI interview. We calculated body mass index as the weight in kilograms divided by the square of the height in meters; a body mass index of less than 18.5 for women and less than 20 for men was considered low (48).

\section{Data Analysis}

Data were entered and imported into an Access 2000 database (Microsoft Corporation, Seattle, WA). We used Statistical Analysis Software (SAS) version 9.1 (SAS Institute, Inc., Cary, NC) for analysis. We compared binary endpoints using the Chisquare test, or Fisher's exact test when the expected frequency of any cell was less than 5 . For continuous variables, we used the t-test, or for non-normally distributed data the Wilcoxon two-sample test.

\section{RESULTS}

Of the 374 individuals in this cohort of tuberculosis patients, 92 (24.6\%) were women. As shown in Table 1, women starting TB treatment tended to be younger ( $\mathrm{p}=0.0007$ ) by approximately 4 years, and were less likely to have a history of incarceration $(p<0.0001)$. Although they presented with a low body mass index more frequently $(\mathrm{p}<0.0001)$, they were less likely to have cavitary and bilaterial lesions on radiograph $(\mathrm{p}=0.01)$ compared with their male counterparts.

Substance use patterns also differed by gender, as shown in Table 2. Smoking was more common and heavier among men $(\mathrm{p}<0.0001)$. Among men, 8.2\% had a lifetime history of drug use disorder, compared with none of the women $(p=0.002)$. Of the patients who completed the written AUDIT questionnaire, the mean score among women was 8.6 ( \pm standard deviation 9.0) while men had a mean score of $14.7 \pm 8.7(\mathrm{p}<0.0001)$. Based on the CIDI questionnaire, $29.7 \%$ of women reported abstinence in the past year compared with $13.1 \%$ of the men, while $11 \%$ of all women and $35.8 \%$ of men reported drinking at least 3 days per week $(p<0.0001)$. Women reported an average of 4.4 standard drinks on a typical drinking day, compared with 12.7 standard drinks among men ( $\mathrm{p}<0.0001)$. According to the CIDI, 16 women $(17.4 \%)$ had an AUD in the past year, while 26 (28.3\%) had a lifetime diagnosis of an AUD, compared with $112(39.7 \%)(\mathrm{p}<0.0001)$ and 199 (70.6\%) ( $\mathrm{p}<0.0001)$, respectively, among men.

Among the 225 individuals diagnosed with a lifetime alcohol use disorder according to the CIDI, we compared consumption, consequences, and health seeking behaviors among men versus women (Table 3). A limitation of these comparisons is the small 
Table 2. Baseline substance use history, $N=374$

\begin{tabular}{|c|c|c|c|}
\hline Variable (N, if not complete cohort) & $\begin{array}{c}\text { Female } \\
\mathrm{N}=92\end{array}$ & $\begin{array}{c}\text { Male } \\
\mathrm{N}=282\end{array}$ & $\mathrm{p}$-value \\
\hline Tobacco use & & & $<0.0001$ \\
\hline Current & $56(60.9)$ & $242(85.8)$ & \\
\hline Ex-smoker & $9(9.8)$ & $28(9.9)$ & \\
\hline Never smoker & $27(29.4)$ & $12(4.3)$ & \\
\hline Pack-years, $N=319$ & $10.7 \pm 9.9$ & $20.8 \pm 17.4$ & $<0.0001$ \\
\hline Drug use disorder (DSM-IV) & $0(0)$ & $7(2.5)$ & 0.34 \\
\hline Drug use disorder (year) & $0(0)$ & $2(0.7)$ & 1.00 \\
\hline Drug use disorder (lifetime) & $0(0)$ & $23(8.2)$ & 0.002 \\
\hline AUDIT score (mean \pm STD) N=364 & $8.6 \pm 9.0$ & $14.7 \pm 8.7$ & $<0.0001$ \\
\hline F requency alcohol consumption, past year, $\mathrm{N}=372$ & & & $<0.0001$ \\
\hline Nearly every day & $5(5.5)$ & $57(20.2)$ & \\
\hline 3- 4 days per week & $6(5.5)$ & $44(15.6)$ & \\
\hline 1-2 days per week & $8(8.8)$ & $50(17.7)$ & \\
\hline 1-3 days per month & $18(19.8)$ & $60(21.3)$ & \\
\hline Less than once a month & $27(29.7)$ & $33(11.7)$ & \\
\hline Did not drink in past year & $27(29.7)$ & $37(13.1)$ & \\
\hline Average standard drinks on drinking days, $\mathrm{N}=373$ & $4.4 \pm 9.4$ & $12.7 \pm 15.0$ & $<0.0001$ \\
\hline Alcohol use disorder, any (past year) & $16(17.4)$ & $112(39.7)$ & $<0.0001$ \\
\hline Alcohol dependence & $9(9.8)$ & $74(26.2)$ & 0.0008 \\
\hline Alcohol abuse & $7(7.6)$ & $38(13.5)$ & 0.14 \\
\hline Alcohol use disorder, any (lifetime) & $26(28.3)$ & $199(70.6)$ & $<0.0001$ \\
\hline Alcohol dependence & $12(13.0)$ & $94(33.3)$ & 0.0001 \\
\hline Alcohol abuse & $14(15.2)$ & $105(37.2)$ & $<0.0001$ \\
\hline
\end{tabular}

sample of 26 women. Although men began drinking an average of two years earlier than women $(p<0.0001)$, the age of onset of alcohol abuse and dependence for men and women were comparable, in the mid-twenties for both sexes. Furthermore, the typical frequency $(p=0.79)$ and consumption $(p=0.29)$ were also comparable among men and women with AUDs, and there was no significant gender difference in the mean number of standard drinks per drinking day of 12.7 versus 16.2 in women and men, respectively ( $p=0.29$ ). Although binge drinking on typical drinking days was more common among men $(\mathrm{p}=0.04)$, this behavior was still frequent among women, reported in $61.5 \%$ of female respondents versus $80.9 \%$ of male respondents. We also explored patients' reports of social consequences of drinking. While fewer women reported jeopardizing their safety due to drinking $(p=0.04)$ or having problems with the police $(\mathrm{p}=0.0006)$, women were more likely to report negative consequences of drinking with their close relationships $(\mathrm{p}=0.01)$. Women were more likely to have attempted to cut down their drinking (61.5\% versus $40.0 \%$, $\mathrm{p}=0.06$ ), although this difference did not reach statistical significance.

\section{DISCUSSION}

In this cohort of individuals starting TB treatment in Tomsk, Siberia, we observed a high prevalence of lifetime AUDs (60.2\%).
Approximately $28 \%$ of women had a lifetime diagnosis of alcohol abuse or dependence, compared with $71 \%$ of all men. To our knowledge, this is the first report to show that, among Russians with lifetime AUDs, women may consume almost as much alcohol as men. In our cohort, drinking patterns among women were not significantly different from those of men, in terms of age of AUD onset, as well as amount of alcohol typically consumed. On the other hand, women in this cohort first began drinking at a later age than men. Our findings are similar to previous reports that have found that women have a 'telescoping' course of alcohol dependence, and that in spite of initiation of use at a later age, the interval from first use to the onset of dependence is shorter than for men $(49,50)$. However, whereas previous studies from alcohol treatment trials have typically found that daily consumption among women is lower than among men $(50,51)$, we found that among those with lifetime AUDs, there was no statistically discernible gender difference in average daily consumption. It is possible that the gender equivalence in mean daily consumption among Russian patients with AUDs seeking treatment for TB, compared with lower reported daily consumption among women compared with men in U.S. alcohol treatment trials, is due to differences in cultural norms $(32,52-55)$ or to other differences in consumption patterns in this population of individuals with co-ocurring TB and AUDs. An alternative explanation of the apparent gender equivalence is the low statistical power of this 
Table 3. Alcohol use patterns among those with DSM-IV lifetime alcohol use disorder, $N=225$

\begin{tabular}{|c|c|c|c|}
\hline Variable (N, if not complete cohort) & $\begin{array}{c}\text { Female } \\
\mathrm{N}=26\end{array}$ & $\begin{array}{l}\text { Male } \\
\mathrm{N}=199\end{array}$ & p-value \\
\hline \multicolumn{4}{|l|}{ Patterns of drinking behavior } \\
\hline AUDIT score, mean \pm STD, $N=216$ & $17.5 \pm 9.0$ & $17.1 \pm 8.1$ & 0.80 \\
\hline Age first began drinking, $\mathrm{N}=224$ & $16.5 \pm 1.9$ & $14.2 \pm 3.9$ & $<0.0001$ \\
\hline Age onset, alcohol dependence, $\mathrm{N}=99$ & $27.6 \pm 10.4$ & $26.8 \pm 7.9$ & 0.77 \\
\hline Age onset, alcohol abuse, $\mathrm{N}=217$ & $27.4 \pm 8.5$ & $25.1 \pm 8.3$ & 0.20 \\
\hline Frequency alcohol consumption, past year & & & 0.79 \\
\hline Nearly every day & $5(19.2)$ & $52(26.1)$ & \\
\hline 3-4 days per week & $4(15.4)$ & $43(21.6)$ & \\
\hline 1-2 days per week & $6(23.1)$ & $37(18.6)$ & \\
\hline 1-3 days per month & $7(26.9)$ & $44(22.1)$ & \\
\hline Less than once a month & $3(11.5)$ & $13(6.5)$ & \\
\hline Did not drink in past year & $1(3.9)$ & $10(5.0)$ & \\
\hline Average standard drinks on drinking days & $12.7 \pm 14.0$ & $16.2 \pm 15.9$ & 0.29 \\
\hline Binge drinking on drinking days ${ }^{a}$ & $16(61.5)$ & $161(80.9)$ & 0.04 \\
\hline \multicolumn{4}{|l|}{ Social consequences in past year, among those actively drinking } \\
\hline Problems with family and/or friends & $20(76.9)$ & $130(65.3)$ & 0.28 \\
\hline Interfered with close relationships, $\mathrm{N}=109$ & $7(50.0)$ & $17(17.9)$ & 0.01 \\
\hline Interfered with social life, $\mathrm{N}=102$ & $7(53.9)$ & $28(31.5)$ & 0.13 \\
\hline Interfered with work & $21(80.8)$ & $144(72.4)$ & 0.35 \\
\hline J eopardized safety & $9(34.6)$ & $115(57.8)$ & 0.04 \\
\hline Problems with police & $5(19.2)$ & $112(56.3)$ & 0.0006 \\
\hline \multicolumn{4}{|l|}{ Help-seeking behavior } \\
\hline Tried but not able to stop/cut down, $\mathrm{N}=224$ & $16(61.5)$ & $80(40.0)$ & 0.06 \\
\hline Talk to health professional & $10(38.5)$ & $50(25.1)$ & 0.16 \\
\hline $\begin{array}{l}\text { Among those who spoke with a health professional, found treat- } \\
\text { ment to be helpful or effective, } N=60\end{array}$ & $7(70.0)$ & $26(52.0)$ & 0.49 \\
\hline $\begin{array}{l}\text { Among those who spoke with a professional, hospitalized for } \\
\text { substance use, } N=60\end{array}$ & $4(40.0)$ & $16(32.0)$ & 0.72 \\
\hline $\begin{array}{l}\text { Among those who spoke with a professional, attended self-help } \\
\text { group, } N=60\end{array}$ & $1(10.0)$ & $1(2.0)$ & 0.31 \\
\hline
\end{tabular}

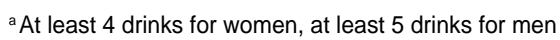

comparison (and others in our study) due to the relatively small number of women with alcohol use disorders $(n=26)$.

Women with AUDs reported high levels of consumption overall, consuming an average of 13 standard drinks per typical drinking day, compared to an average of 16 for men with AUDs. One-third of women with AUDs drank at least three days per week (in comparison to almost half of the men), with $19 \%$ of women drinking nearly every day. Given that the threshold of alcohol consumption associated with increased risk of alcohol-related problems is lower for women compared with men [ $\geq 1$ drinks per day for women, $\geq 2$ drinks per day for men (56)], the women in this cohort are clearly at greater risk for negative health and social consequences of drinking compared to their male counterparts.

The consequences of drinking differed by gender. Although work-related problems due to drinking were common with both genders, women tended to perceive greater social consequences of drinking (for instance, negative effects on relationships).
Conversely, men were more likely to jeopardize their safety or have problems with police while drinking. Women tended to be more active in their attempts to curb their drinking. These results suggest that women with lifetime AUDs in this population could be more receptive to receiving treatment for their drinking. It is possible that efforts to help reduce drinking among women receiving health care for other medical issues (e.g. women's health, tuberculosis, etc.) may be highly effective. Interventions tailored to women that are integrated into primary health care or other medical services may also have the added benefit of diminishing stigma and socio-legal consequences (e.g. loss of child custody, coercive treatment, or employment loss) for women who would otherwise avoid being referred for alcohol treatment in separate, specialized addiction services.

Our study had several limitations. Our cohort was comprised of TB patients in Siberia, thereby limiting the potential generalizability of our findings to other populations in Russia or to populations 
receiving TB care in other countries. However, because patients with tuberculosis often represent the most vulnerable and socioeconomically disenfranchised individuals in many societies (57), we feel that these findings are all the more important to highlight the heightened vulnerability of individuals with co-occurring TB and alcohol use disorders, among women. As previously mentioned, the number of women with alcohol use disorders may have limited our ability to determine statistical significance in some gender comparisons among individuals with AUDs.

In the United States and elsewhere, efforts to better understand gender differences in the antecedents and consequences of alcohol use disorders have informed the design of gender-appropriate interventions to effectively treat AUDs (58-60). To our knowledge, aside from efforts to prevent fetal alcohol syndrome (36), we know of no published efforts to target alcohol interventions specifically for Russian women. Our findings provide additional insight into the characteristics and drinking behavior of women with alcohol use disorders in a highly vulnerable population of Siberian tuberculosis patients. We hope that integrating AUD care into TB services in a gender-sensitive manner will be an effective means of improving health outcomes and psychosocial well-being among marginalized Russian women with AUDs.

\section{Glossary}

Alcohol Use Disorder (as defined by the DSM-IV):

1. A maladaptive pattern of alcohol abuse leading to clinically significant impairment or distress, as manifested by one or more of the following, occurring within a 12-month period:

a) Recurrent alcohol use resulting in failure to fulfill major role obligations at work, school, or home (e.g., repeated absences or poor work performance related to substance use; substance-related absences, suspensions or expulsions from school; or neglect of children or household).

b) Recurrent alcohol use in situations in which it is physically hazardous (e.g., driving an automobile or operating a machine).

c) Recurrent alcohol-related legal problems (e.g., arrests for alcohol-related disorderly conduct).

d) Continued alcohol use despite persistent or recurrent social or interpersonal problems caused or exacerbated by the effects of the alcohol (e.g., arguments with spouse about consequences of intoxication or physical fights).

2. These symptoms must never have met the criteria for alcohol dependence.

Alcohol Dependence: a cluster of behavioral, cognitive, and physiological phenomena that may develop after repeated alcohol use. Typically, these phenomena include a strong desire to consume alcohol, impaired control over its use, persistent drinking despite harmful consequences, a higher priority given to drinking than to other activities and obligations, increased alcohol tolerance, and a physical withdrawal reaction when alcohol use is discontinued.

Alcohol Use Disorder Identification Test (AUDIT):

A method of screening, via brief assessment, for excessive drinking, alcohol dependence, and consequences of harmful drinking published by the World Health Organization (WHO).

Composite International Diagnostic Interview-Substance Abuse Module (CIDI-SAM): a structured clinical interview consisting of questions that are based on the DSM-IV diagnostic criteria for alcohol use disorders.
Diagnostic and Statistical Manual of Mental Disorders, Fourth Edition (DSM-IV): the standard classification manual of currently recognized mental disorders published by the American Psychiatric Association (APA).

International Statistical Classification of Diseases and Related Health Problems 10th Revision (ICD-10): a coding of diseases and signs, symptoms, abnormal findings, complaints, social circumstances and external causes of injury or diseases, as classified by the World Health Organization (WHO).

Tuberculosis (TB): an infectious bacterial disease caused by Mycobacterium tuberculosis, which most commonly affects the lungs. It is transmitted from person to person via droplets from the throat and lungs of people with the active respiratory disease. TB is treatable with a six-month course of antibiotics.

\section{Acknowledgements}

This study was supported by the National Institutes of Health (RO1 AA016318-01), the Eli Lilly Foundation, International Resources \& Exchanges Board Foundation, Whitman Fellowship from Harvard Medical School, and the National Institute on Drug Abuse (K24 DA019855). We also wish to recognize the life-long contributions of Professor Aivar K. Strelis for his excellence in tuberculosis care and research.

\section{REFERENCES}

1. Nemtsov AV. Estimates of total alcohol consumption in Russia, 19801994. Drug Alcohol Depend. 2000 Feb 1;58(1-2):133-42.

2. Cockerham WC, Snead MC, Dewaal DF. Health lifestyles in Russia and the socialist heritage. J Health Soc Behav. 2002 Mar;43(1):42-55.

3. Nemtsov AV. Alcohol-related human losses in Russia in the 1980s and 1990s. Addiction. 2002 Nov;97(11):1413-25.

4. McKee M. Alcohol in Russia. Alcohol Alcohol. 1999 NovDec;34(6):824-9.

5. Medvedev V, Kryshtal T, Heather N. Final report to HLSP consulting on work carried out under project SPS 174: implementing early identification and brief alcohol intervention in primary health care in St. Petersburg, Russian Federation. Geneva: World Health Organization; 2003.

6. Kherosheva T, Thorpe LE, Kiryanova E, Rybka L, Gerasichev V, Shulgina $\mathrm{M}$, et al. Encouraging outcomes in the first year of a TB control demonstration program: Orel Oblast, Russia. Int J Tuberc Lung Dis. 2003 Nov;7(11):1045-51.

7. World Health Organization. The ICD-10 classification of mental and behavioral disorders: diagnostic criteria for research [Internet]. Geneva: World Health Organization; 1993 [cited 2008 Nov 16]. Available from: http://www.who.int/classifications/icd/en/GRNBOOK.pdf.

8. Pakriev S, Vasar V, Aluoja A, Shlik J. Prevalence of ICD-10 harmful use of alcohol and alcohol dependence among the rural population in Udmurtia. Alcohol Alcohol. 1998 May-Jun;33(3):255-64.

9. American Psychiatric Association. Diagnostic and statistical manual of mental disorders DSM-IV. 4th ed. Washington, D.C.: American Psychiatric Association; 1994.

10. World Health Organization. Composite international diagnostic interview 1.1 (CIDI). Geneva: WHO; 1993.

11. Men T, Brennan P, Boffetta P, Zaridze D. Russian mortality trends for 1991-2001: analysis by cause and region. BMJ. 2003 Oct 25;327(7421):964.

12. World Bank. Dying too young: addressing premature mortality and ill health due to non-communicable diseases and injuries in the Russian Federation [Internet]. Washington, D.C.: World Bank; 2005 [cited 2008 Nov 21]. Available from: http://siteresources.worldbank.org/INTECA/ Resources/DTY-Final.pdf.

13. McKee M, Shkolnikov V, Leon DA. Alcohol is implicated in the fluctuations in cardiovascular disease in Russia since the 1980s. Ann Epidemiol. 2001 Jan;11(1):1-6.

14. Ryan M. Alcoholism and rising mortality in the Russian Federation. BMJ. 1995 Mar 11;310(6980):646-8. 
15. Chenet L, McKee M, Leon D, Shkolnikov V, Vassin S. Alcohol and cardiovascular mortality in Moscow; new evidence of a causal association. J Epidemiol Community Health. 1998 Dec;52(12):772-4.

16. Chervyakov VV, Shkolnikov VM, Pridemore WA, McKee M. The changing nature of murder in Russia. Soc Sci Med. 2002 Nov;55(10):1713-24.

17. Aleksandri AL, Konstantinov VV, Deev AD, Kapustina AV, Shestov DB. Alcohol consumption and its connection with mortality from cardiovascular diseases in 40-59 years old men (data from 21.5 year prospective study). Ter Arkh. 2003;75(12):8-12. (In Russian.)

18. Andreev E, Pridemore WA, Shkolnikov VM, Antonova OI. An investigation of the growing number of deaths of unidentified people in Russia. Eur J Public Health. 2008 Jun;18(3):252-7.

19. Leon DA, Saburova L, Tomkins S, Andreev E, Kiryanov N, McKee M, et al. Hazardous alcohol drinking and premature mortality in Russia: a population based case-control study. Lancet. 2007 Jun 16;369(9578):2001-9.

20. Malyutina S, Bobak M, Kurilovitch S, Gafarov V, Simonova G, Nikitin $\mathrm{Y}$, et al. Relation between heavy and binge drinking and all-cause and cardiovascular mortality in Novosibirsk, Russia: a prospective cohort study. Lancet. 2002 Nov 9;360(9344):1448-54.

21. Shkolnikov VM, McKee M, Chervyakov VV, Kyrianov NA. Is the link between alcohol and cardiovascular death among young Russian men attributable to misclassification of acute alcohol intoxication? Evidence from the city of Izhevsk. J Epidemiol Community Health. 2002 Mar;56(3):171-4.

22. Tomkins S, Saburova L, Kiryanov N, Andreev E, McKee M, Shkolnikov $\mathrm{V}$, et al. Prevalence and socio-economic distribution of hazardous patterns of alcohol drinking: study of alcohol consumption in men aged 25-54 years in Izhevsk, Russia. Addiction. 2007 Apr;102(4):544-53.

23. Markov KV, Britov AN, Vedeneeva IA. Incidence of alcohol drinking and the structure of causes of death in men $40-54$ years of age. Sov Zdravookhr. 1990;(4):15-8. (In Russian.)

24. Rehm J, Sulkowska U, Manczuk M, Boffetta P, Powles J, Popova S, et al. Alcohol accounts for a high proportion of premature mortality in central and eastern Europe. Int J Epidemiol. 2007 Apr;36(2):458-67.

25. Solovyov D. New ladies’ vodka gives doctors a headache. Reuters [Internet]; 2008 Mar 17 [cited 2008 Dec 15]. Available from: http://www. reuters.com/article/oddlyEnoughNews/idUSKUA76164020080317.

26. Pomerleau J, McKee M, Rose R, Haerpfer CW, Rotman D, Tumanov S. Hazardous alcohol drinking in the former Soviet Union: a cross-sectiona study of eight countries. Alcohol Alcohol. 2008 May-Jun;43(3):351-9.

27. Malyutina S, Bobak M, Kurilovitch S, Nikitin Y, Marmot M. Trends in alcohol intake by education and marital status in urban population in Russia between the mid 1980s and the mid 1990s. Alcohol Alcohol. 2004 Jan-Feb;39(1):64-9.

28. Department of Mental Health and Substance Abuse. WHO global status report on alcohol. Country profiles: Russian Federation [Internet]. Geneva: World Health Organization; 2004 [cited 2008 Nov 24]. Available from: http://www.who.int/substance_abuse/publications/en/russian_federation. pdf.

29. Laatikainen T, Alho H, Vartiainen E, Jousilahti P, Sillanaukee P, Puska P. Self-reported alcohol consumption and association to carbohydratedeficient transferrin and gamma-glutamyltransferase in a random sample of the general population in the Republic of Karelia, Russia and in North Karelia, Finland. Alcohol Alcohol. 2002 May-Jun;37(3):282-8.

30. Segal BM. The drunken society: alcohol abuse and alcoholism in the Soviet Union. New York: Hippocrene Books; 1990.

31. Kristjanson AF, Wilsnack SC, Zvartau E, Tsoy M, Novikov B. Alcohol use in pregnant and nonpregnant Russian women. Alcohol Clin Exp Res. 2007 Feb;31(2):299-307.

32. Van Gundy K, Schieman S, Kelley MS, Rebellon CJ. Gender role orientations and alcohol use among Moscow and Toronto adults. Soc Sci Med. 2005 Dec;61(11):2317-30.

33. Cockerham WC, Hinote BP, Abbott P. Psychological distress, gender, and health lifestyles in Belarus, Kazakhstan, Russia, and Ukraine. Soc Sci Med. 2006 Nov;63(9):2381-94.

34. Jukkala T, Mäkinen IH, Kislitsyna O, Ferlander S, Vågerö D. Economic strain, social relations, gender, and binge drinking in Moscow. Soc Sci Med. 2008 Feb;66(3):663-74.

35. Abel EL, Sokol RJ. Incidence of fetal alcohol syndrome and economic impact of FAS-related anomalies. Drug Alcohol Depend. 1987 Jan;19(1):51-70.

36. Balachova TN, Bonner BL, Isurina GL, Tsvetkova LA. Use of focus groups in developing FAS/FASD prevention in Russia. Subst Use Misuse. 2007;42(5):881-94.

37. Fleming MF, Krupitsky E, Tsoy M, Zvartau E, Brazhenko N, Jakubowiak $\mathrm{W}$, et al. Alcohol and drug use disorders, HIV status and drug resist- ance in a sample of Russian TB patients. Int J Tuberc Lung Dis. 2006 May;10(5):565-70.

38. Brudney K, Dobkin J. Resurgent tuberculosis in New York City. Human immunodeficiency virus, homelessness, and the decline of tuberculosis control programs. Am Rev Respir Dis. 1991 Oct;144(4):745-9.

39. Døssing M, Wilcke JT, Askgaard DS, Nybo B. Liver injury during antituberculosis treatment: an 11-year study. Tuber Lung Dis. 1996 Aug;77(4):335-40.

40. Fernández-Villar A, Sopeña B, Fernández-Villar J, Vázquez-Gallardo $\mathrm{R}$, Ulloa F, Leiro V, et al. The influence of risk factors on the severity of anti-tuberculosis drug-induced hepatotoxicity. Int J Tuberc Lung Dis. 2004 Dec;8(12):1499-505.

41. Burman WJ, Cohn DL, Rietmeijer CA, Judson FN, Sbarbaro JA, Reves RR. Noncompliance with directly observed therapy for tuberculosis. Epidemiology and effect on the outcome of treatment. Chest. 1997 May;111(5):1168-73.

42. McDonnell M, Turner J, Weaver MT. Antecedents of adherence to antituberculosis therapy. Public Health Nurs. 2001 Nov-Dec;18(6):392-400.

43. Belilovskiy E, editor. Predictive model for treatment interruption among patients with tuberculosis in Russia and Central Asia, former USSR countries. Harvard School of Public Health Practicum. Boston: Harvard School of Public Health; 2005.

44. Pablos-Méndez A, Knirsch CA, Barr RG, Lerner BH, Frieden TR. Nonadherence in tuberculosis treatment: predictors and consequences in New York City. Am J Med. 1997 Feb;102(2):164-70.

45. Toungoussova OS, Sandven P, Mariandyshev AO, Nizovtseva NI, Bjune G, Caugant DA. Spread of drug-resistant Mycobacterium tuberculosis strains of the Beijing genotype in the Archangel Oblast, Russia. J Clin Microbiol. 2002 Jun;40(6):1930-7.

46. Marshall E. Trench warfare in a battle with TB. Science. 2008 Jul 18;321(5887):362-4.

47. Babor TF, Higgins-Biddle JC, Saunders JB, Monteiro MG. AUDIT: the alcohol use disorders identification test. Guidelines for use in primary care. 2nd ed. Geneva: World Health Organization; 2001.

48. Bender D, Bender A. Nutrition: a reference handbook. Oxford: Oxford University Press; 1997.

49. Piazza NJ, Vrbka JL, Yeager RD. Telescoping of alcoholism in women alcoholics. Int J Addict. 1989 Jan;24(1):19-28.

50. Randall CL, Roberts JS, Del Boca FK, Carroll KM, Connors GJ, Mattson ME. Telescoping of landmark events associated with drinking: a gender comparison. J Stud Alcohol. 1999 Mar;60(2):252-60.

51. Anton RF, O’Malley SS, Ciraulo DA, Cisler RA, Couper D, Donovan DM, et al; COMBINE Study Research Group. Combined pharmacotherapies and behavioral interventions for alcohol dependence: the COMBINE study: a randomized controlled trial. JAMA. 2006 May 3;295(17):200317.

52. Triandis HC, Suh EM. Cultural influences on personality. Annu Rev Psychol. 2002;53:133-60.

53. Cockerham WC. The social determinants of the decline of life expectancy in Russia and eastern Europe: a lifestyle explanation. J Health Soc Behav. 1997 Jun;38(2):117-30.

54. Fleming PM, Meyroyan A, Klimova I. Alcohol treatment services in Russia: a worsening crisis. Alcohol Alcohol. 1994 Jul;29(4):357-62.

55. Partanen J. Failures in alcohol policy: lessons from Russia, Kenya, Truk and history. Addiction. 1993 Jan;88 Suppl:129S-34S.

56. Dietary guidelines for Americans 2005 [Internet]. Washington, D.C. U.S. Department of Health and Human Services; 2005 [cited 2009 Mar 30]. Available from: http://www.health.gov/dietaryguidelines/dga2005/ document/pdf/Chapter9.pdf.

57. Addressing poverty in TB control: options for national TB control programmes [Internet]. Geneva: World Health Organization; 2005 [cited 2009 Apr 1]. Available from: http://whqlibdoc.who.int/hq/2005/ WHO_HTM TB 2005.352.pdf.

58. Dawson DA, Grant BF, Li TK. Quantifying the risks associated with exceeding recommended drinking limits. Alcohol Clin Exp Res. 2005 May;29(5):902-8.

59. Force USPST. The guide to clinical preventive services. 2nd ed. Alexandria: Williams \& Wilkins; 1996.

60. Green CA, Freeborn DK, Polen MR. Gender and alcohol use: the roles of social support, chronic illness, and psychological well-being. J Behav Med. 2001 Aug;24(4):383-99. 